\title{
USE OF DIGITAL HOLOGRAPHIC CAMERAS TO EXAMINE THE MEASUREMENT AND UNDERSTANDING OF SEDIMENT SUSPENSION IN THE NEARSHORE
}

\author{
Daniel C. Conley ${ }^{1}$, Daniel Buscombe ${ }^{1}$, and W. Alex M. Nimmo-Smith ${ }^{1}$
}

\begin{abstract}
We present results from a 3-week field experiment measuring surf-zone flows and sediment transport on a steep energetic beach in the south-west UK, including the first reported deployment of an in-line holographic camera ('holocam') in the surf zone, co-located with various optical backscatter sensors and an acoustic backscatter sensor (ABS). The extensive data set provides perhaps a unique opportunity to examine the performance of optical and acoustic backscatter instruments in a wide range of conditions including bubbly flows, as well as some fundamental aspects of sediment suspension processes such as the near-bed size-distribution of suspended sediment. The holocam, deployed with a $1.3 \mathrm{~cm}^{3}$ sample volume approximately $10 \mathrm{~cm}$ above the bed, provides in-focus well-resolved images of the instantaneous suspended load, making it possible to determine highly-accurate estimates of the concentrations of mineral sand grains, bubbles and organic particles, and their size distributions. Instantaneous estimates of sediment concentration from the ABS compare poorly with the equivalent measure from the holocam. This could be due to various factors such as spatial decorrelation or acoustic insensitivities at larger grain sizes. However, the ABS does a very good job at estimating burstaveraged suspended sediment concentrations when bubble concentrations are low (less than $1 \mathrm{ml} / \mathrm{l}$ ). The error in ABS concentrations (as compared against holocam) appears to be related to relative bubble concentration. The OBS is even more sensitive to bubbles. Suspended sediment grain size distribution is skewed towards the finer grain sizes but shifts to the larger sizes with increased flow intensity.
\end{abstract}

Keywords: sediment suspension, surf zone, beach, nearshore, holography, acoustic backscatter sensor

\section{INTRODUCTION}

Determining mobile sediment concentration and particle size distribution is of fundamental importance in sediment transport research. Our understanding of small-scale sediment transport processes and the changing shape, elevation and makeup of the seabed at a single location has traditionally been driven by developments in underwater acoustics and optics to measure flows, morphologies and sediment concentrations at high frequencies (e.g. Downing et al., 1981; Kraus et al., 1994; Agrawal and Pottsmith, 2000). In particular, the development of acoustic and optical backscatter techniques has facilitated the collection of long time series of suspended sediment concentrations at high temporal resolution (e.g. Thorne et al. 1991; Beach et al., 1992).

However, these techniques suffer from the weakness that concentration is a derived quantity obtained from the sensed backscatter level only. This process commonly requires calibration against sediment samples presumed to be equivalent to the sediment being measured. In practice, this is typically achieved by using sediment samples collected from the bed prior to the measurements being collected. The actual calibration process requires that the particles be homogeneously suspended, which in practice is difficult to do (Butt et al., 2002), especially for coarser sands. The appropriateness of this practice is largely dependent on the assumptions that: the makeup of the source bed material remains constant for the period of measurement, the source bed makeup is representative of the sediment which is suspended and that sediment is the dominant scatterer in the water column. In particular, it is currently unknown to what extent bubbles and other non-mineral particles affect optical (Puleo et al., 2006) and acoustic backscatter estimates of mineral sand grain suspensions in a natural surf zone. These assumptions are at the limits of current knowledge and examination of them is rarely performed, largely because this requires direct sampling of the sediment suspensions. In a field setting, such sampling is generally largely cumbersome and impractical for conditions which are rapidly changing.

Whilst multi-frequency acoustic backscatter is capable of returning information on the sizedistribution of suspended particles, much work is still required before it can be applied with confidence in natural settings. Other instruments for measuring in-situ particle size distributions are based on laser diffraction (e.g. Agrawal and Pottsmith, 2000) but instrumentation to date has been bulky and therefore unsuitable for measuring within or close to the wave boundary layer. Pump sampling (e.g. Nielsen, 1983) is logistically very difficult in the field and may preferentially sample certain sizes. In this paper, we report on observations from the simultaneous deployment of a range of sediment concentration sensors including a holographic camera providing direct information on the size- and shape distribution of the suspended sediment load as well as permitting segregation of the suspensate into sediments, organic matter and bubbles.

${ }^{1}$ School of Marine Science and Engineering, Plymouth University, Plymouth, UK 


\section{FIELD EXPERIMENT AND DATA COLLECTION}

A three week field experiment was carried out in May 2011 at Praa Sands, a steep energetic macrotidal beach in Cornwall, UK (Figure 1). Waves, currents, suspended sediment concentrations, and bed elevations/bedforms were measured in a cross-shore and alongshore array across the sub-tidal and intertidal beach face. The tidal range is more than $4 \mathrm{~m}$ on springs which permits instrument deployment and data recovery from non-cabled sensors at low tide. Measurements were collected continuously for 30 tidal cycles (spring to neap to spring) in the surf zone, during a wide range of hydrodynamic conditions (Figure 2).

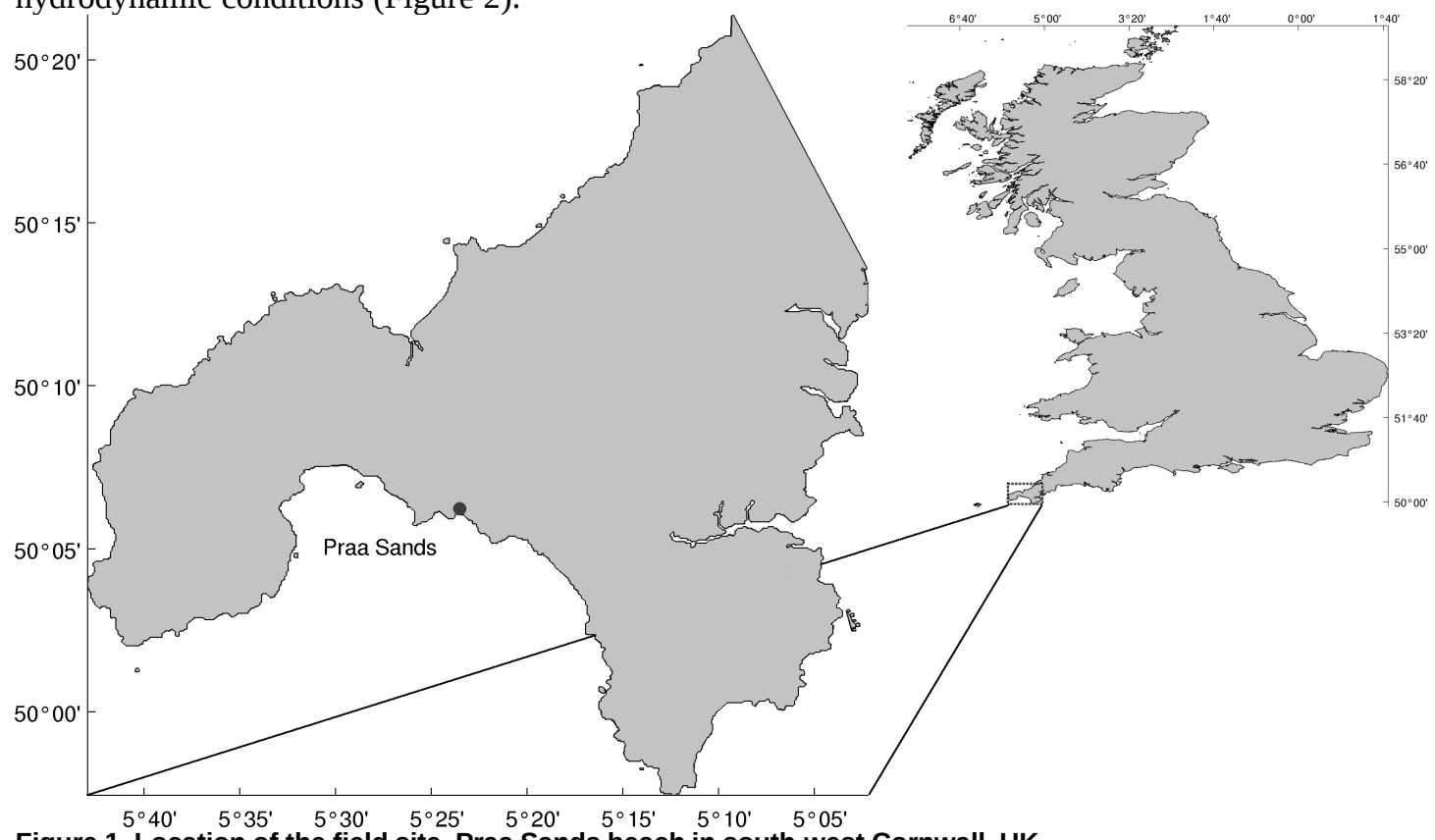

Figure 1. Location of the field site, Praa Sands beach in south-west Cornwall, UK.

One of the goals of the research was to obtain a comprehensive picture of the character of the suspended sediment load. Various sensors were used to collect information on suspended sediment. A multi-frequency (1, 2 and $4 \mathrm{MHz}$ ) acoustic backscatter sensor (ABS, an Aquascat-1000R) was deployed downward looking over up to $80 \mathrm{~cm}$ to the bed (Figure 3), non-intrusively sampling in $5 \mathrm{~mm}$ bins with a transmit pulse length of $5 \mathrm{~mm}$. The sample frequency was $64 \mathrm{~Hz}$, with the data being averaged over $32 \mathrm{~Hz}$ and written to file at $2 \mathrm{~Hz}$. High-frequency hydro-acoustic instruments are sensitive to bubbles, therefore ABS deployments are uncommon in shallow water (inner surf zone) because of breaking-waves and bores creating highly aerated flows. In this macrotidal environment, the ABS returned data from a range of water depths up to $4 \mathrm{~m}$, and from a corresponding range of levels of aeration from bubble-free unbroken waves to highly aerated bores.

A digital in-line holographic camera (hereafter, 'holocam') was deployed during a total of 15 tidal cycles, approximately $50 \mathrm{~cm}$ away from the ABS in the alongshore direction (Figure 3 ). The holocam used is the streamlined version of the nose-to-nose configuration described by Graham and Nimmo-Smith (2010), and consists of a CCD (4.4 $\mu \mathrm{m}$ pixel size) which captures the diffraction patterns of particles created by a collimated 658nm laser beam. Relay lenses and 90 degree mirrors are used within narrow housing extensions which collectively minimise flow disruption adjacent to the sample volume. The holograms, obtained at $5 \mathrm{~Hz}$, were digitally reconstructed at $1 \mathrm{~mm}$ depth intervals over a $1.3 \mathrm{~cm}^{3}$ sample volume approximately $10 \mathrm{~cm}$ from the bed. The holocam is a technology never before deployed in the surf zone. The device has a very low profile (Figure 3) which makes it suitable for deployment close to the bed. Some example raw holograms and montages of reconstructed particles are shown in Figure 4.

In addition, four auxiliary intertidal rigs (10m away in each direction) supported optical backscatter sensors (OBS) measuring voltages related to suspended sediment concentrations at $10 \mathrm{~cm}$ above the bed, and 6MHz Acoustic Doppler Velocimeters (ADVs) measuring flow velocities at $10 \mathrm{~cm}$ above the bed. Acoustic amplitudes measured by ADVs might also be a proxy for suspended fine sediment concentrations (e.g. Chanson et al., 2011) and sand-sized glass beads in the laboratory (Schindler and Robert, 2004) but to our knowledge this is untested for coarse sands in natural flows such as here.

Data from all of the above instruments were compiled for a total of 11 bursts from a range of flow 
conditions and water depths (Table 1). The length of these bursts (order minute) is limited by the manual analysis conducted on the holographic images (see data analysis section below). To date all particles in almost 3000 images have been manually classified and measured.

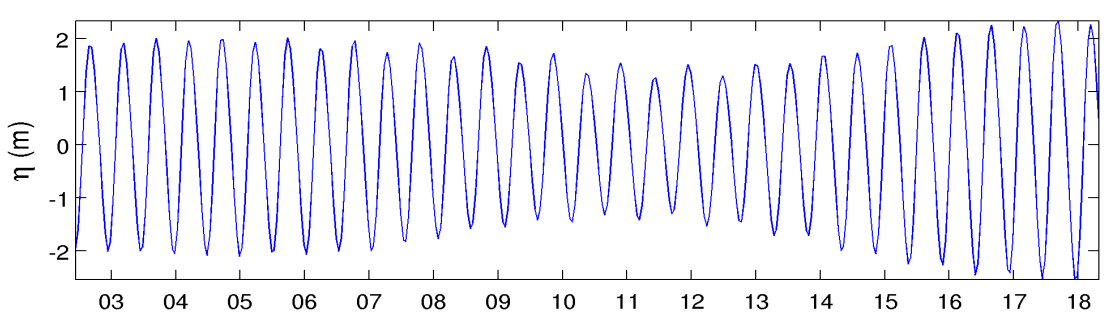

b)

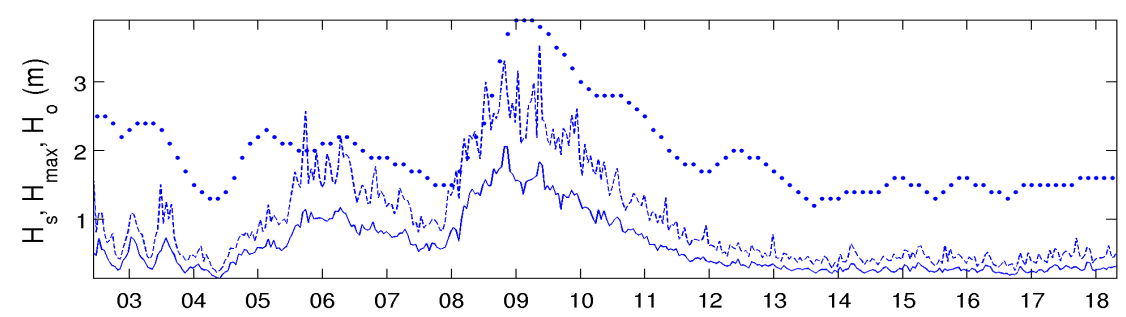

c)

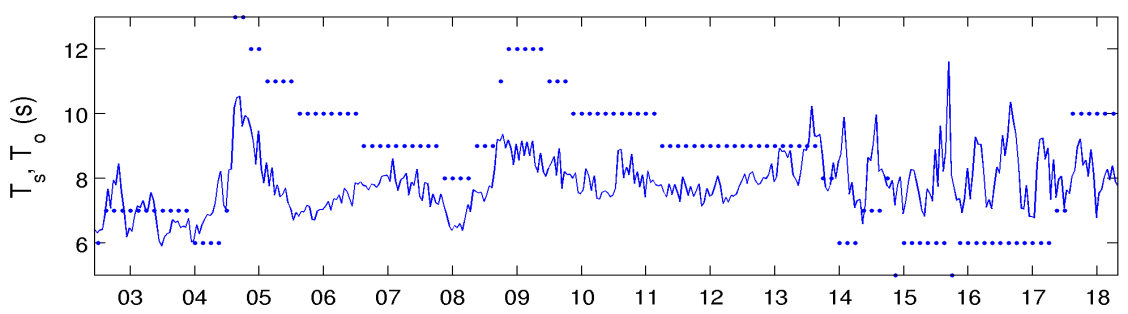

d)

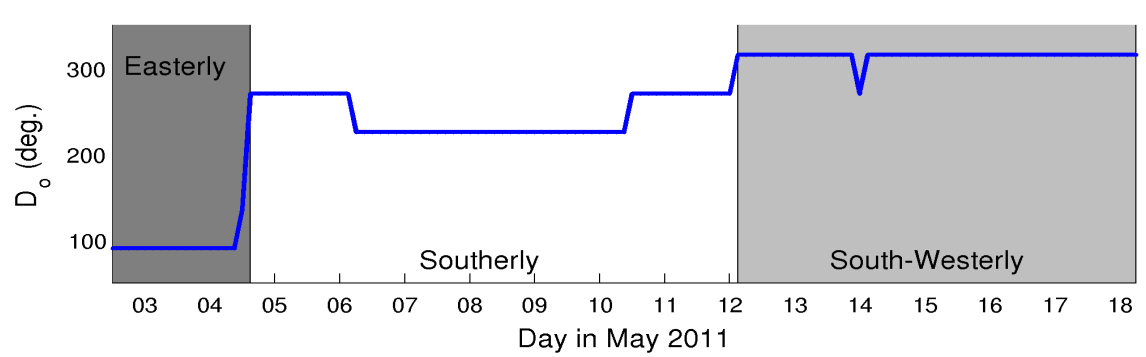

Figure 2. Hydrodynamic conditions during the experiment: a) tide $(m, O D N)$; b) wave height $\left(m, H_{s}\right.$ is significant, $\boldsymbol{H}_{\text {max }}$ is maximum, both in $10 \mathrm{~m}$ water depth immediately offshore of instrumented rigs, and $\boldsymbol{H}_{\mathrm{o}}$ is offshore wave height at the Penzance wave buoy); c) wave period (s, $T_{s}$ is significant in $10 \mathrm{~m}, T_{o}$ is offshore wave period); and d) wave direction (degrees relative to North) at the Penzance buoy.

\begin{tabular}{|l|l|l|l|}
\hline \multicolumn{4}{|l|}{ Table 1. Statistics of analyzed bursts } \\
\hline Burst & Length (s) & Mobility Number (non dim.) & Mean Water Depth (m) \\
\cline { 2 - 4 } 1 & 49 & 73 & 2.5 \\
2 & 59 & 429 & 1.91 \\
3 & 59 & 26 & 0.97 \\
4 & 59 & 9 & 2.77 \\
5 & 30 & 318 & 3.46 \\
6 & 26 & 438 & 0.79 \\
7 & 32 & 341 & 0.81 \\
8 & 59 & 26 & 0.98 \\
9 & 46 & 276 & 1.79 \\
10 & 119 & 15 & 1.32 \\
11 & 62 & 429 & 1.24 \\
\hline
\end{tabular}




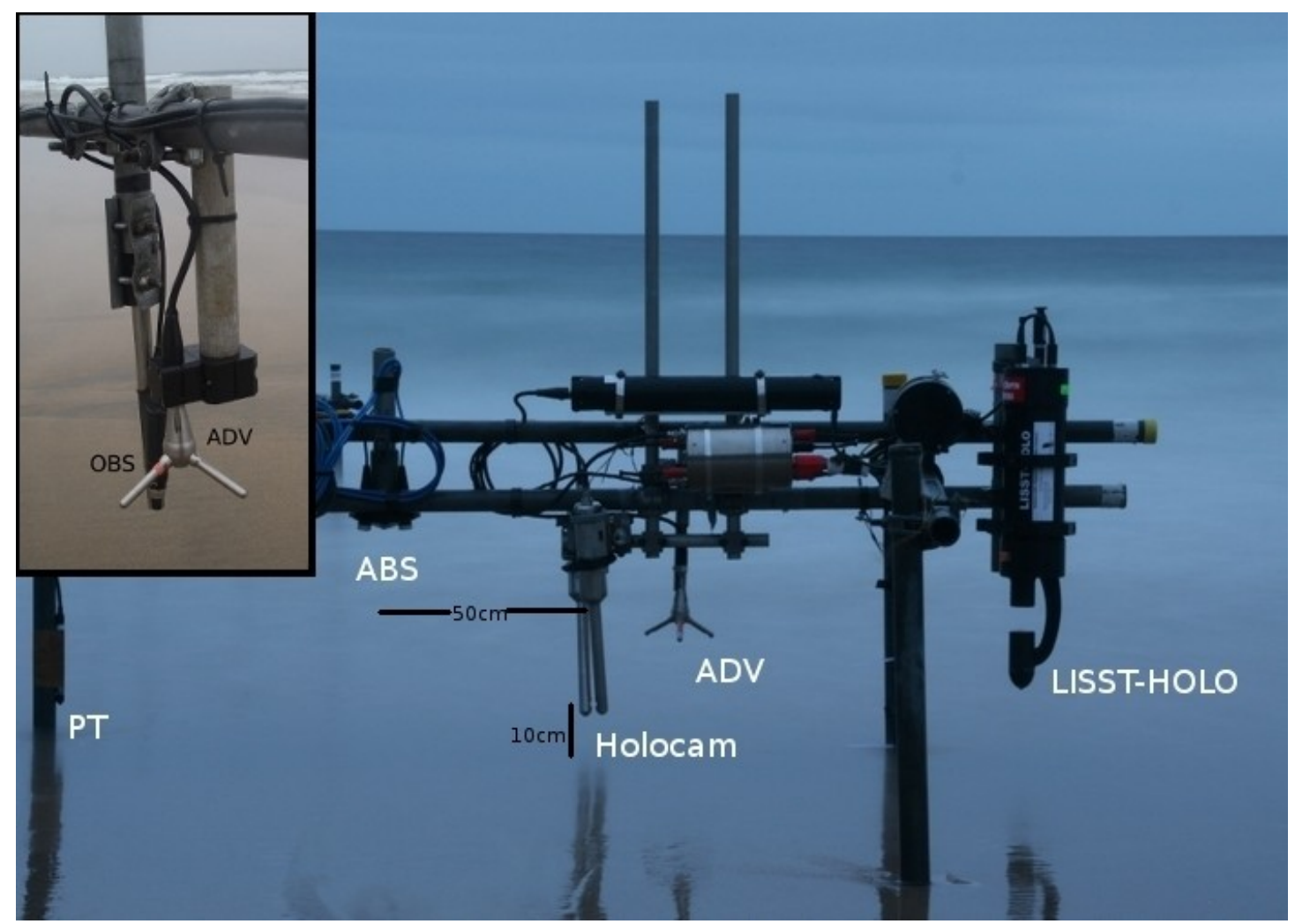

Figure 3. Photographs of some of the intertidal instruments used in this study. The main photograph is of part of the main rig showing the relative locations of the $A B S$, holocam and ADV. The $10 \mathrm{~cm}$ annotation refers to the average distance between the bed and the sample volume. Note that data from the LISST-Holo was not used as part of this study. The inset photograph shows the ADV-OBS configuration of the four auxiliary rigs located $10 \mathrm{~m}$ in each compass direction from the main rig.

\section{DATA ANALYSIS}

Sediment mass-concentration, $M(\mathrm{~g} / \mathrm{L})$, was obtained from the raw voltages returned by the ABS following the implicit iterative approach described by Thorne and Hanes (2002) where:

$$
M_{i}=\left(\frac{V_{r m s_{i}}}{k_{s} k_{t}}\right)^{2} \psi_{i}^{2} r^{2} e^{4 r \alpha_{i}}
$$

where $i$ refer to the three acoustic frequencies; $V_{r m s}$ is the root mean square of the recorded instrument voltage; $\psi$ is an acoustic spreading function; $r$ is the range to the transducer; $\alpha$ is an attenuation coefficient due to water and sediment. Water attenuation is a straightforward function of water temperature, depth and salinity. Sediment attenuation is a function of $r, M$, and a total acoustic scattering cross-section. Scattering is primarily a function of particle shape. Coefficient $k_{t}$ is a constant which depends on the instrument electronics and is provided by the instrument manufacturer. Coefficient $k_{s}$ is a function of the attenuation of sound due to sediment, sediment density, and sediment form function which describes the backscattering characteristics of the sediment suspension. Coefficient $k_{s}$ has been obtained using natural sand following the methods outlined in Betteridge et al. (2008) using hollow spherical glass balls in the range 297-354 $\mu \mathrm{m}$ using $1 \mathrm{~cm}$ bins.

Raw holograms were processed to reconstruct focused silhouettes of all the particles in the sample volume (Figure 4) using a similar automated methodology as described by Graham \& Nimmo-Smith (2010) and Graham et al. (2012). The automated processing cannot classify particles by type, so each image was also processed manually in order to identify and classify the particles by eye and to obtain cross-sectional areas and other metrics of particle size. This permits estimation of concentrations and the distributions of particle size and shape, separately for sand grains, organic matter and bubbles. Here, we restrict the analysis to just results from the manual measurements from the holocam. Volumes were obtained from the visible cross-sectional areas using an equivalent circular area diameter. 
ADV backscatters were averaged over all three channels. OBS raw counts were not calibrated, because the response should be linearly related to suspended sediment concentration (Downing, 2006).
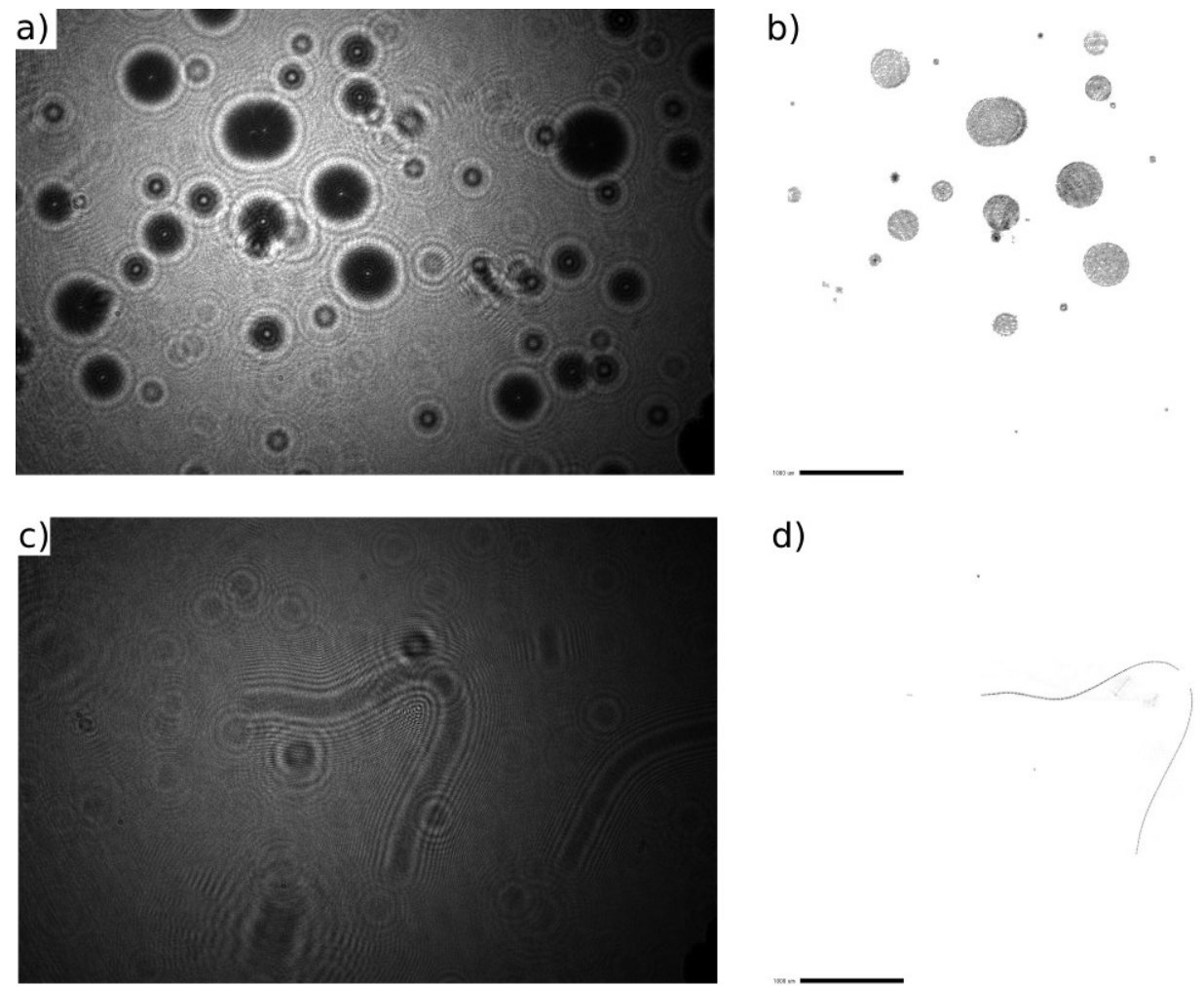

d)

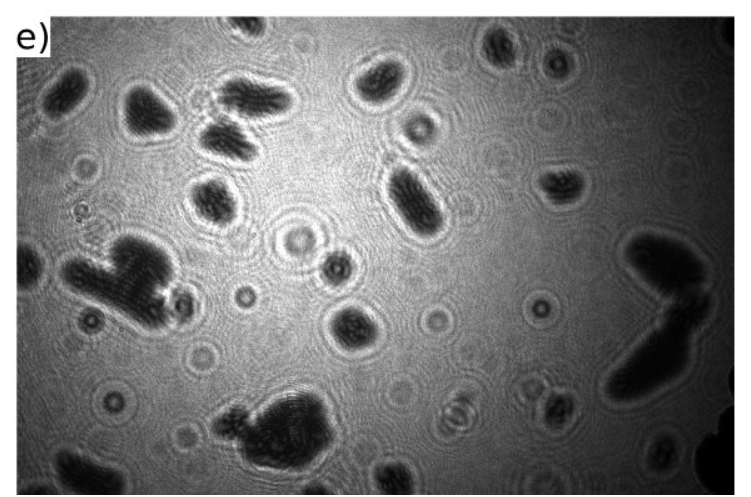

f)

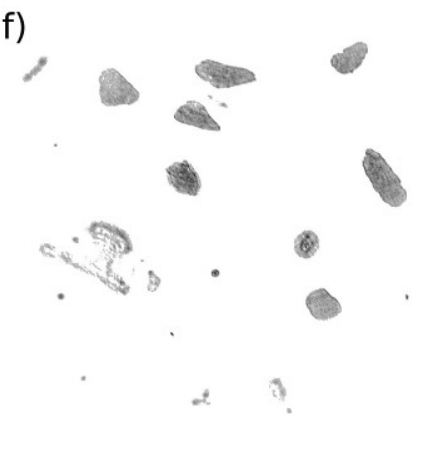

Figure 4. Raw holograms (left) and adjacent reconstructed montages of in focus particle silhouettes (right). The top image ( $a$ and $b$ ) shows a particularly bubbly flow. The middle row (c and d) is an example of long diatom chains in suspension. The bottom image ( $e$ and $f)$ shows a high concentration sand suspension. The scale bars on the right montages are $1 \mathrm{~mm}$.

\section{RESULTS}

Time-series of instantaneous sediment concentrations from holocam (down-sampled to $2 \mathrm{~Hz}$ ) and ABS (2Hz) vary considerably (Figure 5). Correlations based on all $2 \mathrm{~Hz}$ data from all 11 bursts are very low $(r=0.14$, Figure 6$)$. Note that only the sand concentration from the holocam is considered in Figure 5 and 6 . These 11 bursts represent a range of suspensions, for example very shallow heavily aerated flow (bores); non-aerated diatom-dominated suspensions; and aerated/non-aerated sanddominated suspensions. A range of relative proportions of grains, bubbles and organic material for some bursts are shown in Figure 7 to illustrate this variability. 

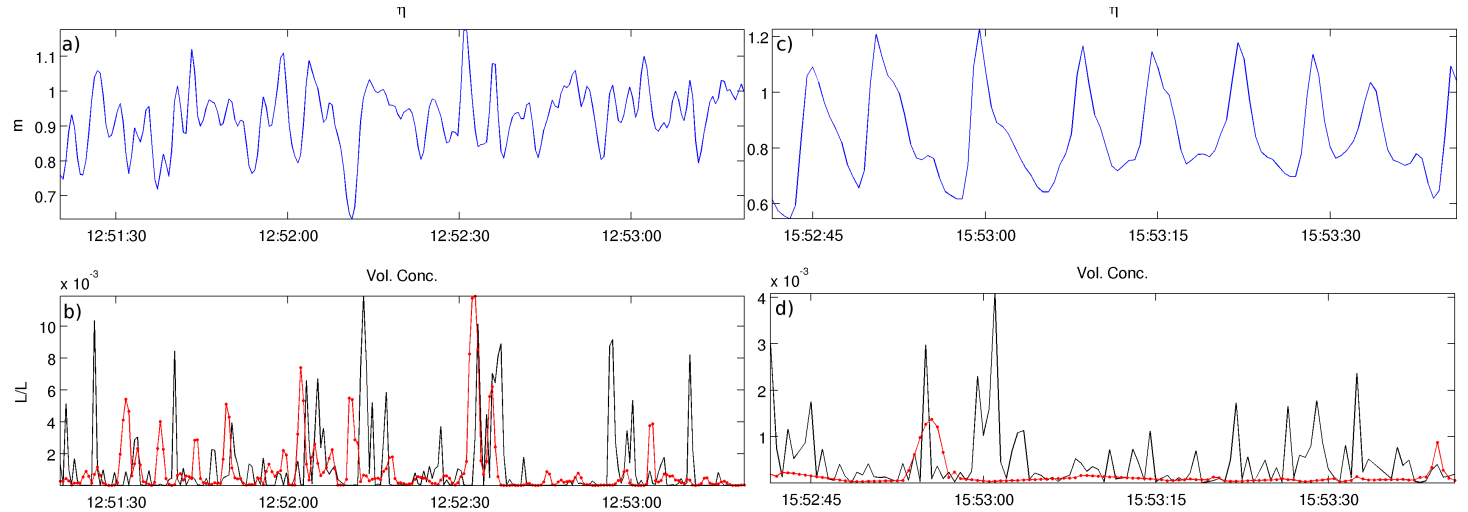

Figure 5. Example sea surface elevation ( ${ }^{12}$, top) ${ }^{12: 52: 33: 00}$ and volumetric suspended sediment concentration (bottom) from burst 10 (left: $a$ and b) and burst 11 (right: $c$ and d). In plots b and d, the solid lines are from the holocam (down-sampled from 5 to $2 \mathrm{~Hz}$ ) and the dotted lines are the concentration from the same height above the bed as measured by the ABS (at $2 \mathrm{~Hz})$.

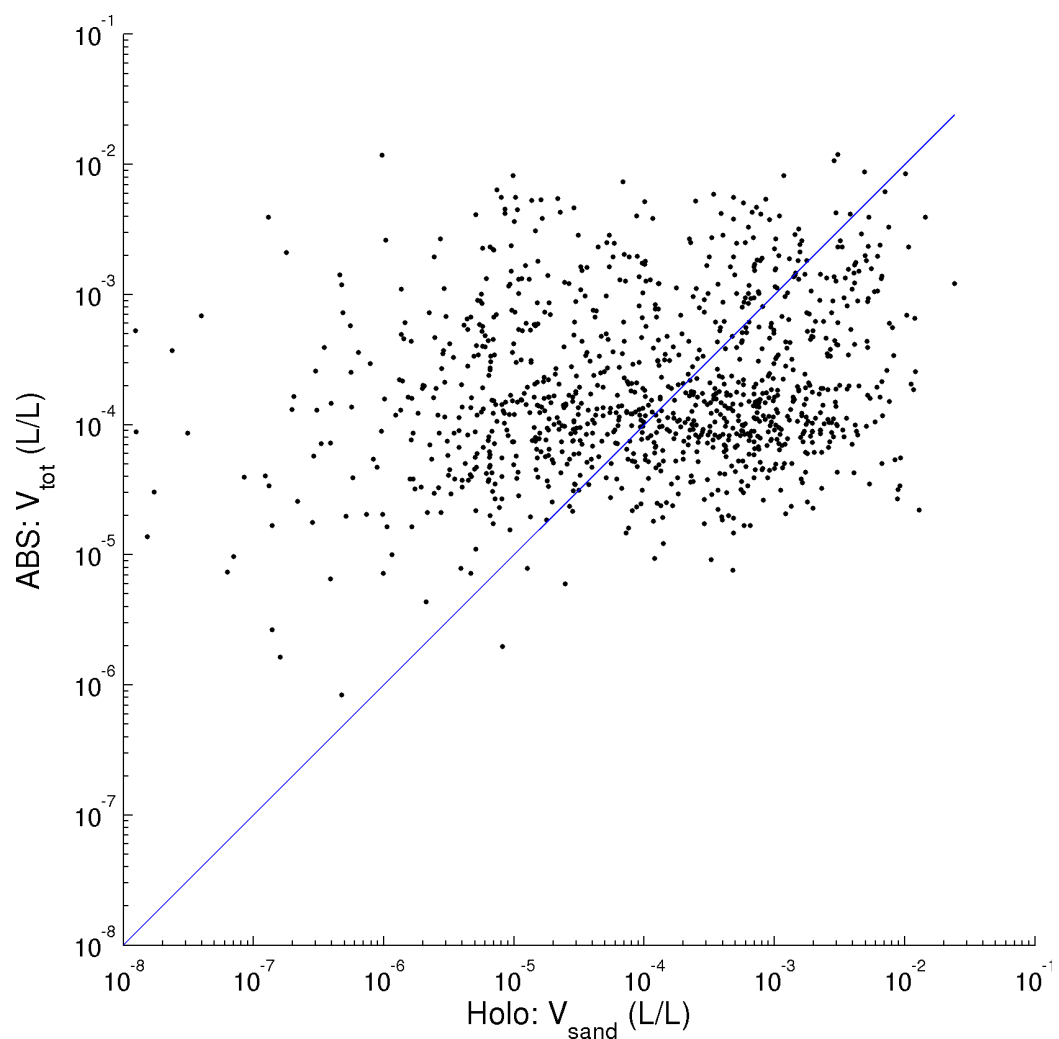

Figure 6. Comparison between instantaneous $(2 \mathrm{~Hz})$ volumetric sand concentrations as determined from the ABS and from the holocam. The solid line is the 1:1: comparison.

When burst-averaged, however, the agreement between the holocam and ABS concentrations improves significantly (Figure 8) with a correlation coefficient of 0.87 . This high correlation suggests that the advection length scale for instantaneous sediment suspension is less than the separation between the instruments. The correlation increases to 0.98 when bursts with time-averaged volumetric bubble concentration more than $1 \mathrm{ml} / \mathrm{l}$ are ignored. In fact, there's a clear (though nonlinear) relationship between burst-averaged bubble concentration and burst-averaged squared discrepancy between concentration estimates of both instruments (Figure 9), suggesting that the ABS progressively under-predicts sand concentrations with increasing water aeration.

It can further be demonstrated that bubble proportions are proportional to, and also that diatom proportions are inversely proportional to, mobility number (Figure 10) given by: 


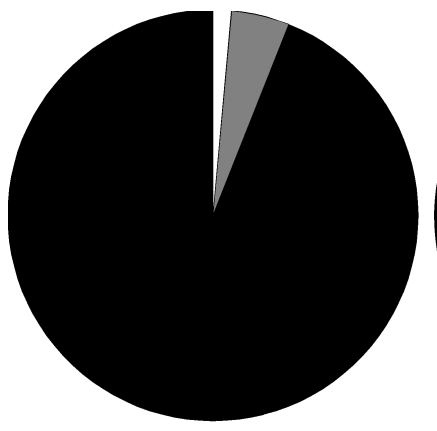

BURST 9

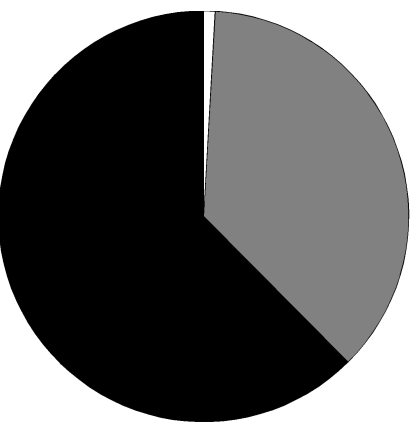

BURST 3

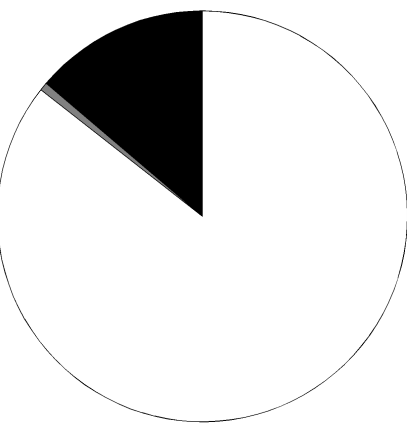

BURST 7

Sand

Bubbles

Diatoms

Figure 7. Relative proportions of volumetric concentrations of sand, bubbles and diatoms for three example bursts. These bursts represent end members of the spectrum of 11 bursts analyzed.

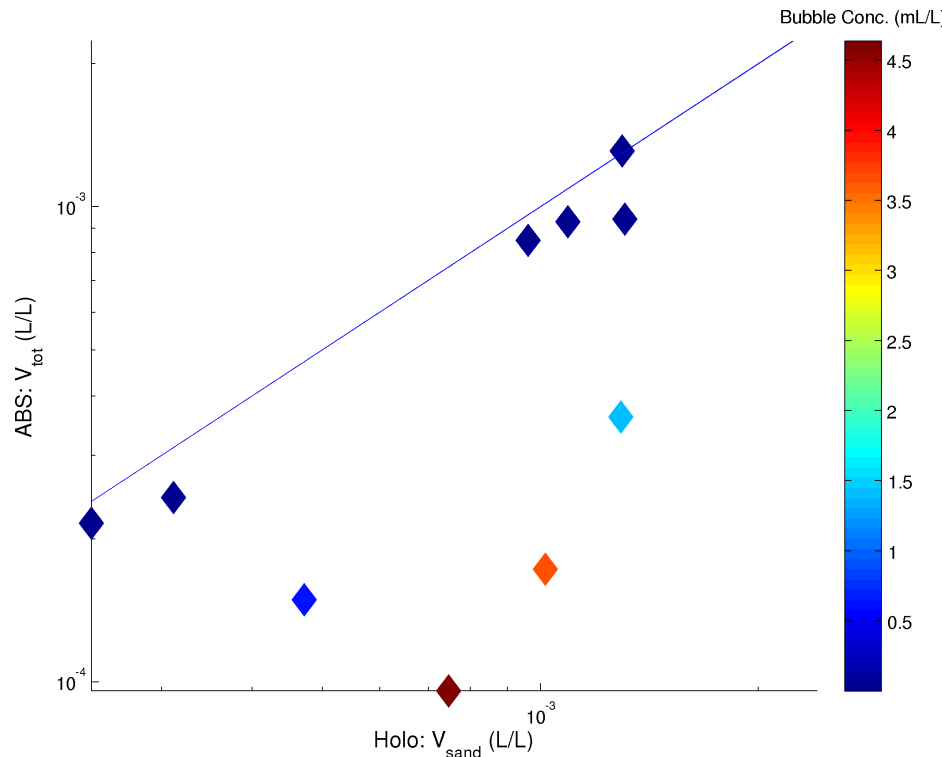

Figure 8. Comparison between burst-averaged volumetric sand concentrations as determined from the ABS and from the holocam. The solid line is the 1:1: comparison. The marker shade shows the average bubble volumetric concentration for that burst.

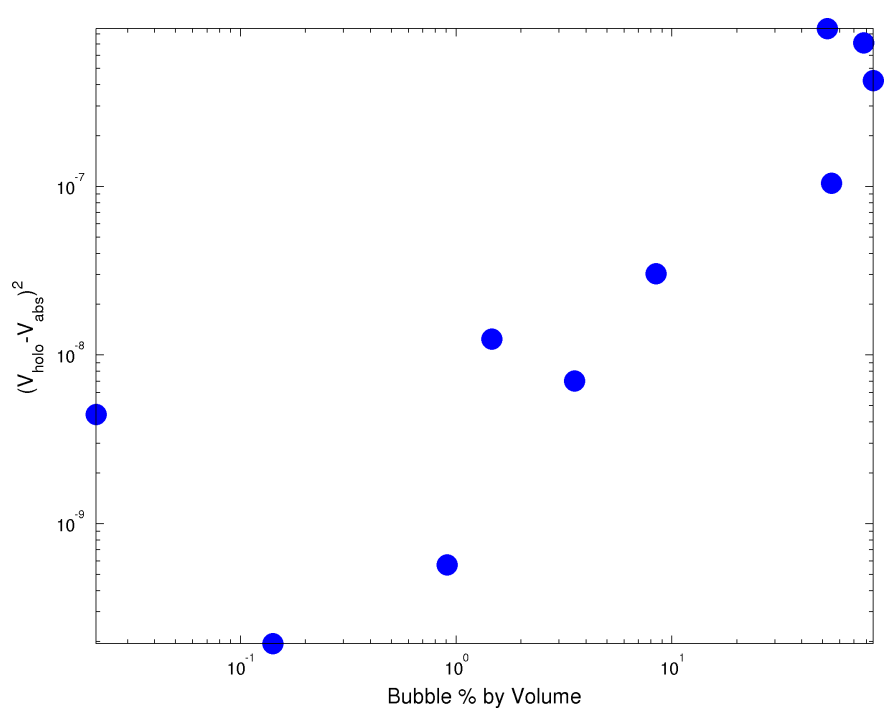

Figure 9. Squared burst-averaged discrepancy between sand concentration estimates from holocam and ABS versus burst-averaged percentage volumetric bubble content. 


$$
\Psi=\frac{u_{\max }^{2}}{\left(\rho_{s} / \rho-1\right) g D}
$$

where $u_{\max }$ is peak velocity during the burst, $D$ is bed sediment mean grain size (325 $\left.\mu m\right), g$ is gravitational acceleration, $\rho_{s}$ and $\rho$ are sediment and fluid densities, respectively. This suggests that there might be simple predictable relationships between mobility number and bubbles which in turn might affect shear stress estimates.

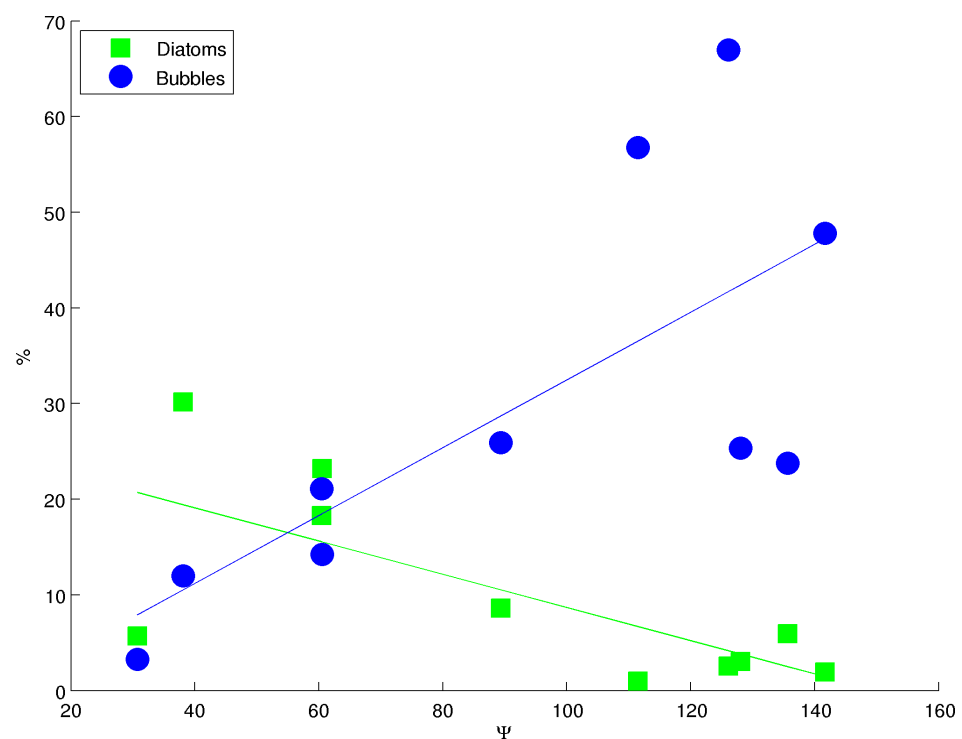

Figure 10. Percentage of suspensate composed of bubbles (circles) and diatoms (squares) as a function of mobility number. Solid lines are linear least-squares fits.

Opportunities to examine the size-distribution of near-bed suspensions are exceedingly rare in the field, so the measurements from the holocam are valuable even though only a single height above the bed is sampled. In general, the data indicate the suspended material is significantly finer than the source (bed) sediment (Figure 11), implying selective suspension and possibly spatial sorting of grain size on the foreshore. Burst-averaged size-distributions in lower intensity flows are biased towards the finer grains. As flow intensity, or relative wave height, increases mean grain size increases (Figure 12). This coarsening and broadening of the suspended sand size distribution is indicative of a finesediment supply limitation and is likely to be related to the specific bed sediment distribution at this site rather than a general finding.

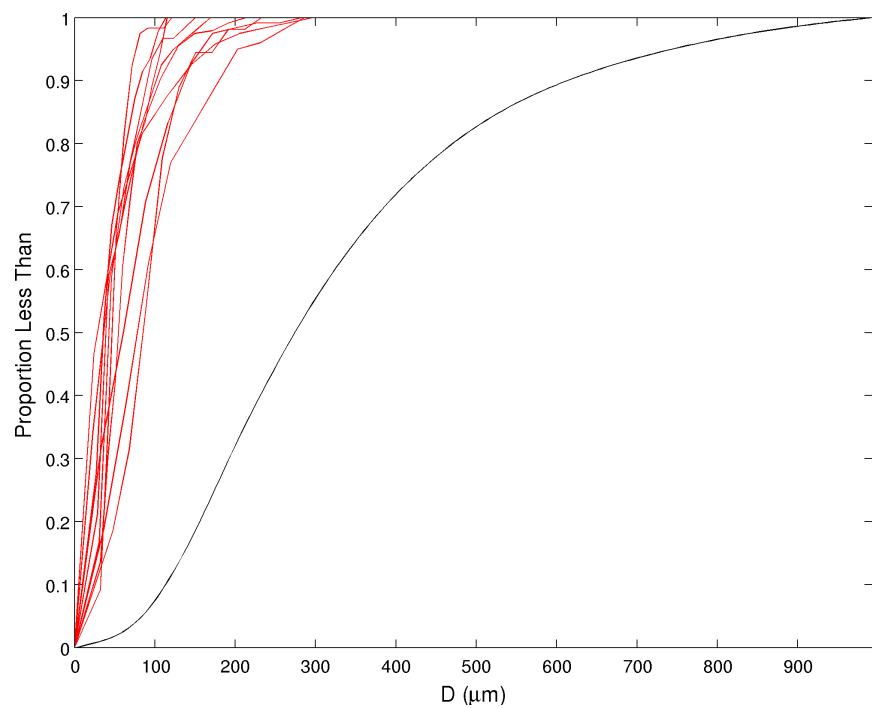

Figure 11. Cumulative grain size distributions of the bed sediment (dark line); and suspended sediment (lighter lines) per burst at $10 \mathrm{~cm}$ above the bed. 

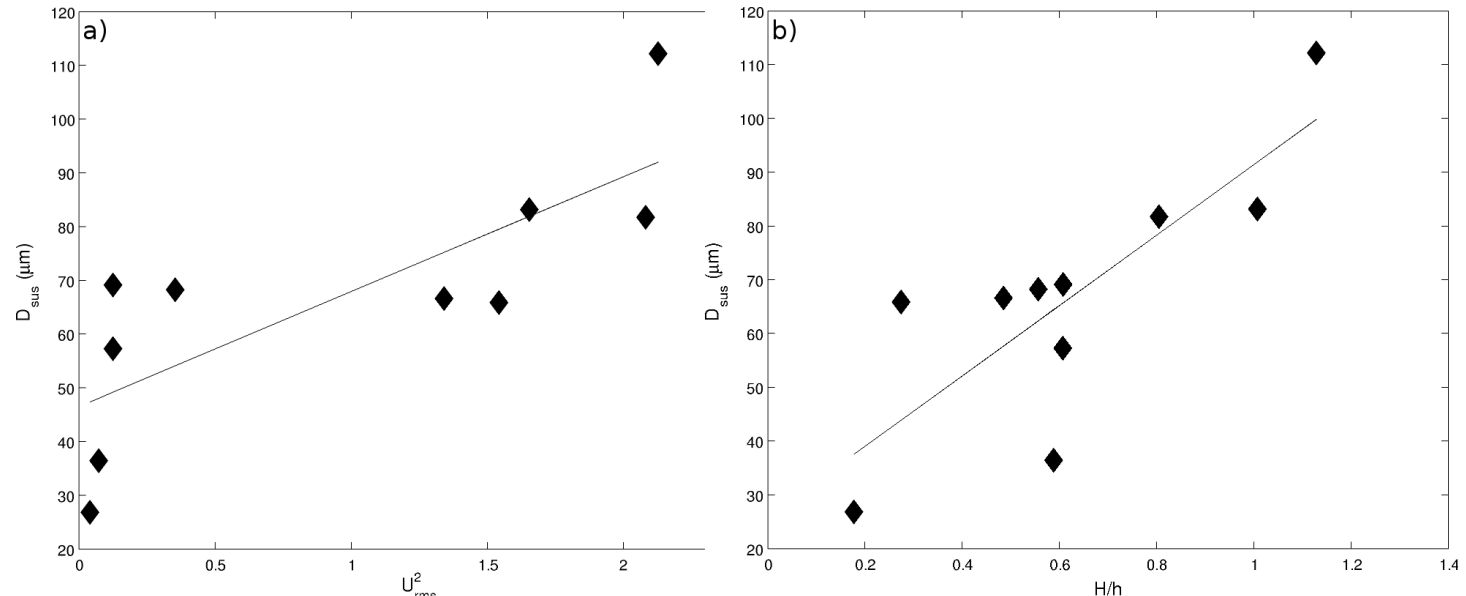

Figure 12. Burst-averaged sand size in suspension ( $\left.D_{\text {sus }}\right)$ versus: a) squared r.m.s velocities per burst; and b) relative wave height per burst.

The relationship between burst-averaged sand concentrations from the holocam and the timeaveraged raw voltage response from OBS sensors is weak (Figure 13a; correlation is 0.22), but improves significantly when compared to the total particulate and bubble concentrations from the holocam (Figure 13b; correlation is 0.67 ) suggesting that the OBS is particularly sensitive to bubbles (c.f. Puleo et al., 2006).
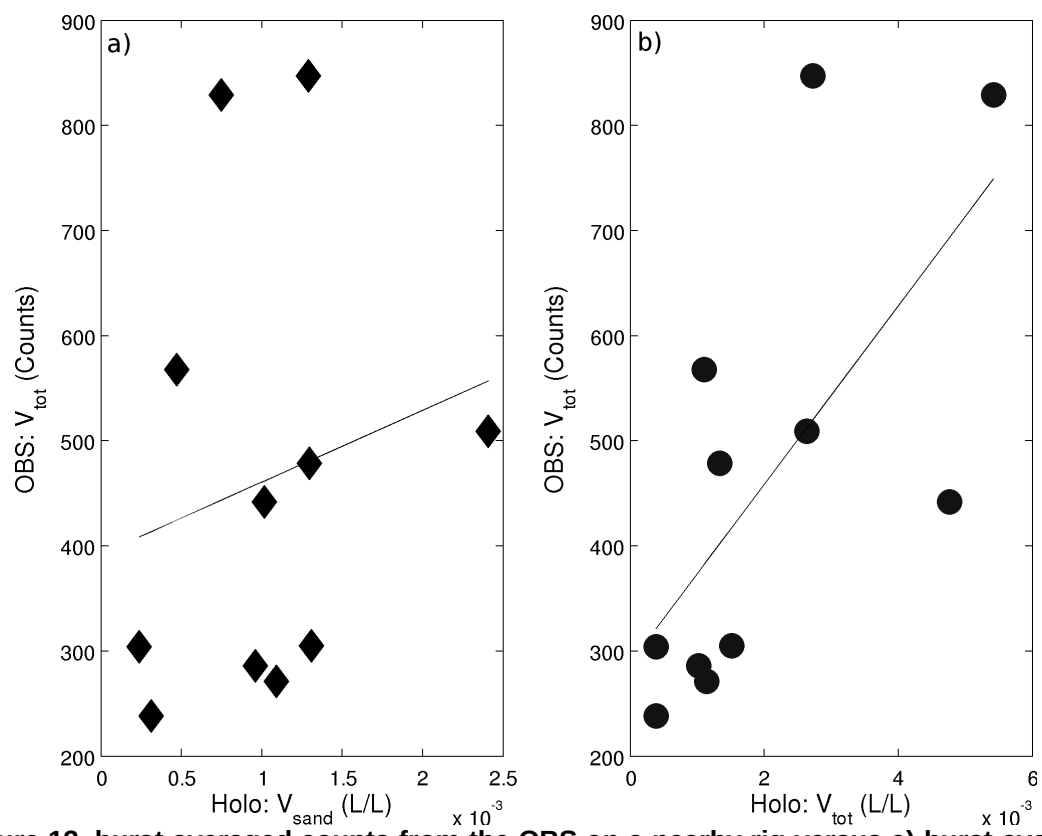

Figure 13. burst-averaged counts from the OBS on a nearby rig versus a) burst-averaged sand concentrations from holocam; and b) burst-averaged total concentrations (sand plus bubbles plus organic material) from the holocam.

Finally, it's interesting to compare the holocam-derived sand concentrations with acoustic backscatter from the ADV. Correlations were always greater in the vertical direction, but nevertheless poor $(0.3$ to 0.4$)$ and did not improve when those bursts where the mean bubble concentrations were less than $1 \mathrm{ml} / \mathrm{l}$ were discounted (Figure 14). These results suggest that the ADV at this frequency $(6 \mathrm{MHz})$ is not a suitable instrument for estimating suspended sand concentrations.

\section{DISCUSSION}

The data set reported here represents possibly a unique opportunity to compare the response of various acoustic and optical sensors to the same sediment-laden flows, in a harsh environment where attenuation by bubbles tends to damp the signal from suspended mineral sand grains. Manual estimates of concentration and particle size from the focused images of sand grains provided by the holocam are not without errors (human error associated with digitizing particle outlines and 
misclassification of particle type) however they represent possibly the closest to a 'gold standard' achieved to date.

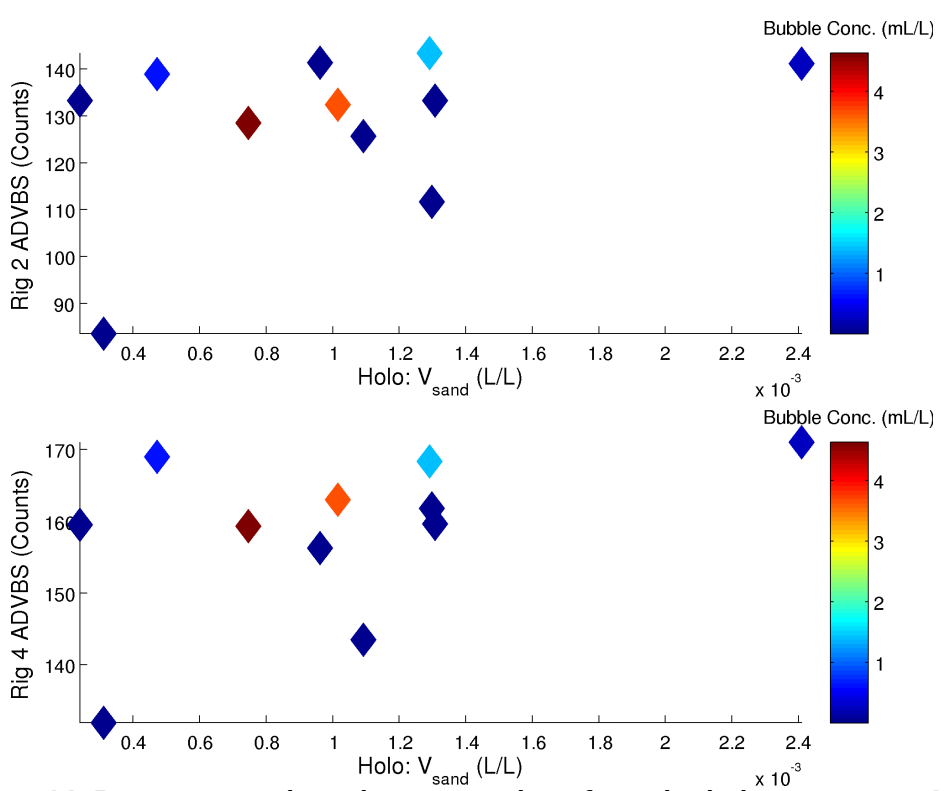

Figure 14. Burst-averaged sand concentrations from the holocam versus ADV backscatter from two different instruments (top and bottom) located approximately $10 \mathrm{~m}$ away from the holocam.

Possible explanations for the large discrepancy between the instantaneous sand concentration estimates from the holocam and ABS could potentially be due to differences in sensor response to grain-size which average out over bursts however, the most likely explanation is related to the correlation length scale of instantaneous sediment concentration.

The high performance of the ABS for burst-averaged estimates of sediment concentration is due to the combination of suspended grain size and acoustic frequencies which provide large acoustic sensitivities. The acoustic sensitivity (AS) to a sediment particle at a given concentration can be written (Thorne and Hanes, 2002):

$$
A S \propto \sum_{n} \frac{F_{n}^{2}}{a_{n}}
$$

where $F$ is the form function (describing backscatter) and $a$ particle radius of the $n$th size-class. The form factor is proportional to $k a^{2}$ where $k=2 \pi f / c$ is the acoustic wave-number. Assuming a spherical particle, acoustic sensitivity peaks at $k a=1$ (i.e. when particle circumference is close to the acoustic wavelength). During our deployments acoustic sensitivities were high, for example $0.21<k a<0.84$ (increasing with frequency) for a $100 \mu \mathrm{m}$ suspended particle. However, for the large suspended grains $k a$ can be much greater than 1 , for example $0.52<k a<2.09$ for a $250 \mu \mathrm{m}$ particle. It is therefore possible that the ABS performance deteriorates when suspended particles are larger in the stronger flows, which we shall be investigating in the future. The ABS is relatively unaffected by the presence of diatoms whose $k a$ are in the region 0.05 .

\section{CONCLUSIONS}

An in-line holographic particle imaging system (holocam) was used to examine the concentrations and size-distributions of suspended sands in the wave-dominated surf zone. The holocam was deployed along with a multi-frequency acoustic backscatter sensor (ABS) and various OBS and ADVs from which suspended sediment concentration estimates may be obtained from the backscatter characteristics. Instantaneous sediment concentrations from the ABS and holocam are poorly correlated on a short time response basis but do exhibit co-responsiveness over longer time scales. The apparent contradiction here is most probably due to spatial decorrelation. However, the agreement between burst-averaged volumetric concentrations from the holocam and ABS is very good when the bubble concentrations are small (nominally, less than $1 \mathrm{ml} / \mathrm{l}$ ). The squared discrepancy scales nonlinearly with bubble volumetric concentration. Suspended organic matter (at this site primarily diatom chains) in general appear to make little difference to the ABS estimates of sediment 
concentration. Suspended sediment distributions coarsen and broaden with flow intensity, leading to the mean grain size increasing linearly with mean squared flow velocities. In turn, this suggests that the pick up of coarse grains increases with stronger flows but also that the bed source distribution limits the suspension of fines.

\section{ACKNOWLEDGMENTS}

The work was funded by a (UK) Natural Research Council grant (NE/G007543/1) awarded to D.C. and A.N.S. Thanks to James Sawyer for carrying out manual particle identification and sizing on thousands of holographic images. Image processing was carried out using holoproc software (http://holoproc.marinephysics.org/). Thanks to Aline Pieterse, Peter Ganderton, Megan Sheridan, and a small army of field volunteers from the Coastal Processes and Marine Physics research groups at Plymouth University.

\section{REFERENCES}

Agrawal, Y.C., and H.C. Pottsmith. 2000. Instruments for particle size and settling velocity for observations in sediment transport, Marine Geology, 168, 89-114.

Beach, R.A., R.W. Sternberg, and R. Johnson. 1992. A fiber optic sensor for monitoring suspended sediment, Marine Geology, 103, 513-520.

Betteridge, K.F.E., P.D. Thorne, and R.D. Cooke. 2008. Calibrating multi-frequency acoustic backscatter systems for studying near-bed suspended sediment transport processes, Continental Shelf Research, 28, 227-235.

Butt, T., J. Miles, P. Ganderton, and P. Russell. 2002. A simple method for calibrating optical backscatter sensors in high concentrations of non-cohesive sediments, Marine Geology, 192, 419424.

Chanson, H., D. Reungoat, B. Simon, P. Lubin. 2011. High-frequency turbulence and suspended sediment concentration measurements in the Garonne River tidal bore, Estuarine Coastal and Shelf Science, 95, 298-306.

Downing, J.P., R.W. Sternberg, and C.R.B. Lister. 1981. New instrumentation for the investigation of sediment suspension processes in the shallow marine environment, Marine Geology, 42, 19-34.

Downing, J.P. 2006. Twenty-five years with OBS sensors: The good, the bad, and the ugly, Continental Shelf Research, 26, 2299-2318.

Graham, G.W., and W.A.M. Nimmo-Smith. 2010. The application of holography to the analysis of size and settling velocity of suspended cohesive sediments, Limnology and Oceanography: Methods, 8, 1-15.

Graham, G.W., E.J. Davies, W.A.M. Nimmo-Smith, D.G. Bowers, and K.M. Braithwaite. 2012. Interpreting LISST-100X measurements of particles with complex shape using digital in-line holography, Journal of Geophysical Research, 117, C05034.

Kraus, N.C., A. Lohrmann, and R. Cabrera. 1994. New acoustic meter for measuring 3D laboratory flows, Journal of Hydraulic Engineering, 120, 406-412.

Nielsen, P. 1983. Entrainment and distribution of different sand sizes under water waves, Journal of Sedimentary Petrology, 53, 423-428.

Puleo, J.A., R.V. Johnson, T. Butt, T.N. Kooney, and K.T. Holland. 2006. The effect of air bubbles on optical backscatter sensors, Marine Geology, 230, 87-97.

Schindler, R.J., and A. Robert. 2004. Suspended sediment concentration and the ripple-dune transition, Hydrological Processes, 18, 3215-3227.

Thorne, P.D., and D.M. Hanes. 2002. A review of acoustic measurement of small-scale sediment processes, Continental Shelf Research, 22, 603-632.

Thorne, P.D., C.E. Vincent, P.J. Hardcastle, S. Rehman, and N. Pearson. 1991. Measuring suspended sediment concentrations using acoustic backscatter devices, Marine Geology, 98, 7-16. 